\title{
Advancing Patient Engagement in Health Service Improvement: What Can the Evaluation Community Offer?
}

\author{
Nathalie Gilbert and J. Bradley Cousins \\ University of Ottawa
}

\begin{abstract}
Despite efforts for greater patient engagement in health care quality improvement, evaluation practice in this context remains mostly conventional and noncollaborative. Following an explication of this problem we discuss relevant theory and research on patient-centred care (PCC) and patient engagement and then consider potential benefits of collaborative and participatory approaches to evaluation of such initiatives. We argue that collaborative approaches to evaluation (CAE) are logically well-suited to the evaluation of PCC initiatives and then suggest contributions that the evaluation community can offer to help advance patient engagement. Finally, we outline a research agenda that identifies important areas that are in need of further examination.
\end{abstract}

Keywords: collaborative approaches to evaluation, health quality improvement, participatory evaluation, patient-centred care, patient engagement, program evaluation

Résume : Malgré les efforts consentis pour mieux faire participer les patients dans l'amélioration de la qualité des soins de santé, la pratique d'évaluation dans ce contexte reste généralement conventionnelle et non collaborative. Après avoir décrit le problème, nous discutons des théories et des recherches pertinentes dans le domaine des soins axés sur le patient et de son engagement, avant de nous pencher sur les avantages possibles des approches collaboratives et participatives en évaluation pour de telles initiatives. Nous avançons que les approches collaboratives en évaluation sont particulièrement adaptées à l'évaluation d'initiatives de soins axés sur les patients et suggérons des moyens que la communauté en évaluation contribue à la promotion de la participation des patients. Finalement, nous identifions des priorités de recherche dans des secteurs d'importance où une réflexion approfondie est nécessaire.

Mots clés : approches collaboratives en évaluation, amélioration des soins de santé, évaluation participative, soins axés sur les patients, participation des patients, évaluation de programme

Corresponding author: Nathalie Gilbert, University of Ottawa, Faculty of Education; nathalie.gilbert@sympatico.ca 


\section{STATEMENT OF THE PROBLEM}

Health organizations are increasingly making efforts to offer patient-centred health services that are more responsive to patients' preferences, values, and needs. The underlying philosophy of patient-centred care (PCC) advocates for patients to have an active role in all areas of their care, including broader areas of the health care system such as planning and evaluation of health services (Gerteis, Edgman-Levitan, Daley, \& Delbanco, 1993; Stewart et al., 2000). The conceptualization of PCC emerged during the 1950s and is widely used in health organizations to refer to an essential component of quality health care. The concept of PCC was originally introduced as a rejection of the traditional model of care that tended to be more disease- and physician-focused, toward a health care that is more holistic in nature and aims to improve the patient experience. Studies have demonstrated that PCC, with its emphasis on being responsive to patient preferences and needs, has positive outcomes on the quality of health care and is strongly desired by patients and families (Agency for Health Care Research and Quality, 2005; Little et al., 2001; Rao, Weinberger, \& Kroenke, 2000).

Current strategies used for the assessment and monitoring of PCC and patient experience tend to be primarily based on performance measurement and patient/ family feedback (Baker, 2014; Davies \& Cleary, 2005). For example, patient satisfaction surveys are commonly used for reporting on the quality of health services as well as to inform decision-making. Considered one of the gold standards in health care quality improvement, patient satisfaction surveys have a wide range of validated surveys available that are low-cost, can gain large amounts of feedback, can be easily implemented, and can provide hospitals with an opportunity to receive posthoc feedback from patients (Canadian Foundation for Healthcare Improvement [CFHI], 2012; Veillard et al., 2005). Yet, as reported by the CFHI, there is a myth in health care that "high patient satisfaction means high quality care" (2012, p. 1). Martin and Ronson (2007) caution that an approach in which health organizations rely on patient satisfaction surveys to identify areas that need improvement and to learn more about the patient experience is insufficient. They concluded that "fifty years of patient satisfaction research has found that in study after study between 80 and $90 \%$ of patients are satisfied" $(2007$, p. 8). Some of this could be explained by the fact that most patient satisfaction surveys tend to ask surface-level questions (i.e., discrete, categorical questions about delivery of care), are subject to self-selection and literacy bias, and are therefore limited in capturing the patient's experience beyond the questions being asked (CFHI, 2012; Williams, Coyle, \& Healy, 1998). Other forms of feedback also commonly used in tapping into patient views about patient experience include interviews, complaints, and patient or family narratives. They are beneficial in capturing patient experience information, but tend to focus on individual issues, are resource intensive, and often challenge decision makers on how to incorporate these data into quality improvement plans (Baker, 2014).

Another common practice in health care quality improvement efforts is the use of performance measurement systems, which monitor the performance 
of the broader health care system using statistical data to determine progress toward specific defined objectives (Adair et al., 2006). Health decision makers use performance monitoring data by monitoring selected indicators and targets to help assess their performance over time and to make comparisons with other health institutions that offer similar services. Performance data serve an important role in ensuring health organizations meet their accountability requirements established by their funding agencies. They are also regularly used to help inform health professionals and decision makers on how health consumers use the health system (e.g., number of emergency department visits, wait times) as well as for establishing strategic directions. However, an important limitation is the relative lack of health performance systems that include indicators that can further our understanding of patients' health service experiences, integral to improving PCC (Canadian Institute for Health Information [CIHI], 2016). One explanation for this may be that patients or family members are not regularly involved or consulted in the development of health services indicators. That is, performance indicators are typically developed through provincial or state requirements, research evidence, and consensus of an expert panel, usually comprised of health professionals without input from patients or family members (Baker, Fancott, Judd, \& O'Connor, 2016). As a result, performance data often fall short in terms of informing decision makers about issues that are of importance to patients and families. For example, administrators, clinicians, and patients give importance to different aspects of care, and their ideas on quality health services differ (Kötter, Schaefer, Scherer, \& Blozik, 2013). Administrators tend to be concerned with operational efficiency (e.g., bed occupancy, budget), clinicians are interested in clinical efficiency (e.g., mortality rates, complications) and patients tend to be more concerned with the health care experience and interpersonal interactions with health providers (Ioan, Nestian, \& Tiţă, 2012). Arguments have been made for greater involvement of patients and family members in indicator development and selection to collect performance data that is more reflective of patient and family priorities and to better understand the patient experience (Gagliardi, Lemieux-Charles, Brown, Sullivan, \& Goel, 2008a, 2008b; Kötter et al., 2013). Recently, the $\mathrm{CIHI}$ has taken the lead in making efforts to address the indicator gaps related to measuring patient experience and are in the process of developing "a set of indicators to measure patient experience, inform performance improvements over time, and support benchmarking across Canada" (CIHI, 2016, p. 2). This is an important contribution to health performance systems and will certainly advance health professional and decision makers' abilities to consider and better understand patient experiences. However, key challenges that will remain are the ability to gain a true understanding of the local context of patient experience as well as explaining the variance in results.

The use of performance measurement and patient feedback is well entrenched within the health sector and highly valued by decision makers. These strategies serve important functions in terms of meeting accountability requirements and monitoring patient satisfaction. Yet, despite efforts to collect these forms of data, 
the application of quality improvement strategies that would facilitate patientcentredness across organizations remains a challenge and has had mixed results (Baker, 2014; International Alliance of Patients' Organizations [IAPO], 2007; Ponte et al., 2003; Robinson, Callister, Berry, \& Dearing, 2008). For example, Baker (2014) reviewed how patient engagement contributes to improved care, reporting that decision makers have reported feeling challenged in linking these data sources to answer key priority questions. Overall, efforts made toward developing sophisticated measures for capturing patient experience have not led to improved knowledge on how to apply these results as a means to improving patient experience. Baker (2014) noted, "While data and stories about patients are important sources of information, they may be insufficient to motivate and focus improvement in many contexts" (p. 2).

The Institute of Medicine report, Crossing the Quality Chasm (IOM, 2001), has been influential and has received widespread support within health care for applying more patient-focused quality improvement strategies. These strategic efforts toward increasing patient engagement are geared toward addressing some of the gaps identified in the use of conventional quality improvement strategies as well as to improve the quality of patient-centred health services. More recently, there has been a sharp increase in the number of government and nongovernmental organizations sponsoring and advocating for greater patient engagement activities across all levels of health care (e.g., quality improvement, accreditation, strategic planning, research, etc.). Two of many examples are the Patients First: Action Plan for Health Care that made a commitment "to expand patient engagement" in Ontario (Ministry of Health and Long-Term Care, 2015) and Canada's Strategy for Patient-Oriented Research, providing a "continuum of research that engages patients as partners, focusses on patient-identified priorities and improves patient outcomes. This research, conducted by multidisciplinary teams in partnership with relevant stakeholders, aims to apply the knowledge generated to improve healthcare systems and practices" (Canadian Institutes of Health Research, 2016, para 2).

To date there is limited empirical research that has examined the effects of patient engagement or the best approach to engage patients (Abelson et al., 2015; Baker, 2014). Furthermore, there is a relative lack of collaboration and shared knowledge between the evaluation community and health sector in the rapidly developing area of patient engagement and the development of best practices. As a consequence, health organizations continue to struggle on how best to involve patients (i.e., process) in health service improvement initiatives as well as learn from patient experience (Baker, 2014; Luxford, Safran, \& Delbanco, 2011). In this article we make the argument that the evaluation community could offer significant contributions in these areas through the promotion of evaluation approaches that are collaborative and participatory-approaches that are logically and conceptually aligned with PCC initiatives.

With greater attention and efforts being made toward patient engagement in the planning, design, and evaluation of health services, it is critical to identify 
strategies to continue the advancement of patient engagement as complementary to improving patient-centred health services. Health organizations have made efforts to increase patient engagement efforts, but some of these developments have not always been as productive and effective as originally intended. In this article, we discuss the relevant literatures of PCC and patient engagement to further our understanding of some of the challenges and facilitators that might allow patient engagement to prosper. Following this discussion, we offer the use of collaborative approaches to evaluation (CAE), such as practical participatory evaluation (P-PE), as potentially powerful facilitators of patient engagement that are currently missing. Through collaborative practices we believe the evaluation community can help advance patient engagement in health care quality. Finally, we outline a research agenda that identifies several important areas that are in need of further examination. We begin by providing an overview of the evolutionary trajectory of PCC, providing a conceptual perspective for discussing some of the facilitators, barriers, and approaches to patient engagement.

\section{PATIENT-CENTRED CARE}

The conceptualization of PCC emerged during a time of substantive change in health care, changes that saw the introduction of new technologies, specialties, and patient populations. PCC is entrenched in health organizations to refer to an essential component of quality health care. Despite difficulties defining the term, by the late 1990s there were some general principles associated with PCC, many of which were based on the seminal work produced by the Picker Commonwealth Program for Patient-Centred Care, now known as the Picker Institute, which is considered to be one of the more influential organizations for advancing PCC (Shaller, 2007). The Picker inquiry, led by Gerteis et al. (1993), conducted a wide range of focus groups of recently discharged patients, family members, physicians, and nonphysician hospital staff as well as reviewed pertinent literature related to PCC. Seven key principles of PCC were identified through this work, which culminated in the publication of a book entitled Through the Patient's Eyes (Gerteis et al., 1993). The fundamental PCC principles identified in their work were

- $\quad$ respect for patients' values, preferences, and expressed needs;

- coordination and integration of care;

- information, communication, and education;

- $\quad$ physical comfort;

- emotional support and alleviation of fear and anxiety;

- involvement of family and friends; and

- $\quad$ transition and continuity. (p. 223)

Subsequent to the publication of this book, there was a significant increase in the interest in PCC across health care systems and significant uptake in the efforts to define PCC (IAPO, 2007). For example, in its landmark report, Crossing the 
Quality Chasm, the IOM (2001) included PCC as one of their six aims for health care improvement and declared that "making care more patient-centred means adjusting nearly every aspect of practice, in every realm from the administrative to the clinical to the technological" (p. 1).

Despite the prominence given to PCC within the health care system, implementation of effective PCC practices remains a challenge (Luxford et al., 2011; Shaller, 2007). Identification and distinction of PCC definitions within the different health care contexts in which it is being applied could assist health care providers in improving the implementation of PCC. For example, Robinson et al. (2008) found that most PCC definitions are derived from four distinct sources: a public policy perspective, an economic perspective, a clinical perspective, and a patient perspective. The PCC perspectives that Robinson et al. (2008) have suggested deconstruct the PCC concept into more manageable and contextspecific components. These four proposed PCC perspectives challenge health organizations to focus their PCC efforts at all levels of the health care system and organization. Significant efforts have been made in the past decade, using a bottom-up approach, to improving PCC practices within the patient and clinical $P C C$ perspectives that take place at the individual patient level. However, one area of development that deserves greater attention is exploring PCC practices aimed at the broader, organizational level of health programs and organizations (IAPO, 2007). Robinson et al. (2008) refer to this as the public policy perspective of PCC, and it serves as the foundation for all other PCC practices and sets the direction for PCC across health care. Patient engagement in setting research priorities or in the planning and evaluation of health services are examples of PCC being implemented at the organizational level, which is the focus of this article.

Despite considerable efforts in applying quality improvement efforts (e.g., incident reporting, clinical audit, risk management, etc.), health organizations have had mixed results in implementing widespread patient-centredness (Luxford et al., 2011; Shaller, 2007). However, further research has examined critical organizational facilitators to promoting successful implementation of PCC. The most critical include (a) a strong and committed leadership (i.e., CEO and board of directors), identified as critical for achieving sustained delivery of PCC; (b) a strong and clearly communicated strategic vision that was constantly communicated to every member of the organization; (c) systematic measurement and regular feedback to health service providers (e.g., front-line staff, decision makers, etc.) of patient experience data with high specificity; (d) involvement of patients and families at multiple levels (e.g., service redesign, partners in care, patient and family advisories, representation on medical executive committees, etc.); and (e) a culture that strongly supports change and collective learning, identified as a powerful enabler to PCC (Luxford et al., 2011).

While the concept of PCC is well entrenched in health care, there continue to be challenges in its meaning and implementation. The factors contributing to successful implementation of PCC outlined in the previous section may provide some insight into practices that elevate the norm. In response to the continuing 
challenge of incorporating widespread patient-centredness across health organizations, momentum is building and there is commitment within the health sector to seriously support activities that engage patients in health care quality improvement efforts.

\section{PATIENT ENGAGEMENT}

The following review of the relevant patient engagement literature is based on material acquired through systematic searches of the knowledge base using standard computerized search and retrieval tools. Specifically, we sought empirical and conceptual published research in comprehensive health management databases using Medline (Ovid), Allied and Complementary Medicine, Embase, Healthstar, PsycINFO, and Cochrane Database of Systematic Reviews using the keywords "patient engagement" and "patient involvement." Sources addressed the following questions: (a) How is patient engagement defined/described for health care quality improvement? (b) What are the facilitators and challenges to patient engagement in planning and evaluation of health services? (c) What does the approach or process used for engagement look like? The search was limited to the years 2000 to present and targeted peer-reviewed published work. In addition to the computerized search, we used bibliographic follow-up to identify relevant publications.

This led us to a body of knowledge that promotes patient engagement in planning and evaluation as a means of addressing PCC at the broader level of a health program or organization. The terminology surrounding patient engagement, patient involvement, public engagement, and public involvement in health care is quite varied. All of these terms share the common goal of seeking public or patient input and guide health system decision-making on specific health care issues (Abelson et al., 2016). The term public engagement appears to be used as an umbrella term in the literature for public involvement in health decision-making; other terms such as patient engagement/involvement tend to have more limited specific meanings and different intensities of engagement (Hill, O'Grady, Millar, \& Boswell, 2000; Mitton, Smith, Peacock, Evoy, \& Abelson, 2009). Abelson et al. (2015, p. 2) describe public and patient engagement as a "term to capture a wide range of efforts aimed at actively involving citizens and patients in various domains and stages of health system decision-making." This article is only concerned with the patient perspective rather than the broader societal public perspective; therefore, the term patient engagement will be used to represent the active engagement of patients, including family members, in health service planning and evaluation. The CFHI has been at the forefront of supporting patient engagement initiatives and describes patient engagement as

initiatives that engage patients and families in designing, delivering, and evaluating health services, with the goal of improving the quality of care. Co-designing improvements with patients and families leads to new insights and better results than providers and leaders working on their own. (CFHI, 2017) 
Patient engagement gained considerable attention in North America and Europe more than a decade ago, and the practice of patient engagement for health service improvement has evolved considerably in Canada (Abelson et al., 2015; CFHI, 2017; Crawford et al., 2002; Van de Bovenkamp, Trappenburg, \& Grit, 2010). The United Kingdom and the Netherlands have been at the forefront of developing strategies for patient engagement (e.g., experience-based co-design, Bate \& Robert, 2007) as well as conducting empirical studies examining the effects of patient engagement (Crawford et al., 2002; Fudge, Wolfe, \& McKevitt, 2007; Van de Bovenkamp et al., 2010). In Canada, efforts toward greater patient and family engagement for improving patient experience have been more recent. For example, the Change Foundation, an independent policy think tank, added a strategic priority that "will focus on listening and learning to better understand the family caregiver experience as part of the patient experience and to identify promising models or initiatives for effective and collaborative engagement between family caregivers and providers" to their 2015-2020 strategic plan (Change Foundation, 2015 p. 16). Cancer Care Ontario's 2011-2015 Ontario Cancer Plan identified "continue to assess and improve the patient experience" as one of their six strategic priorities (Cancer Care Ontario, 2011, p. 40). Efforts toward increased patient engagement in quality improvement have become priorities for many health organizations as a means of improving patient experience, but progress has been limited (Baker, 2014; Baker et al., 2016).

Carman et al. (2013) have made significant contributions in defining and describing what is involved with patient engagement and proposed a multidimensional framework for patient and family engagement in health and health care. The framework describes the levels at which patient engagement can occur across the health care system, from direct care to patient engagement into organizational design, evaluation, governance, and policy-making. The framework depicts how much information is exchanged between patient and provider as well as how active a role the patient has along the continuum of engagement. For example, at the continuum's lower end, which tends to be consultative in nature, "patients are involved but have limited power or decision-making authority. Providers, organizations, and systems define their own agendas and then seek patients' input. Information flows to patients and then back to the system" (Carman et al., 2013, p. 224). At the higher end of the patient engagement continuum, "engagement is characterized by shared power and responsibility, with patients being active partners in defining agendas and making decisions. Information flows bidirectionally throughout the process of engagement, and decision-making responsibility is shared" (Carman et al., 2013, p. 224).

There is limited empirical research that has examined the process, effects, and best approaches for engaging patients in health organizational design/governance, evaluation, and policy (Armstrong, Herbert, Aveling, Dixon-Woods, \& Martin, 2013; Baker, 2014; Baker et al., 2016). The following section provides an overview of the literature on the facilitators and challenges of patient engagement in the planning and evaluation of health services that go beyond direct care. 


\section{Strengths and Facilitators of Patient Engagement}

Baker and Denis (2011) identified patient engagement initiatives as a means to better respond to patients' needs and expectations as well as a priority area for system change within Canada. They also suggested that patient engagement is increasingly being seen as a "potentially strong lever to shift the system toward improvement and to align the perspectives and activities of different practitioners" (p. 25).

Review of patient engagement studies indicates that there has been a positive impact in the following areas: improved educational or tool development (Baker et al., 2016), possibly improved clinical care outcomes or service delivery (Baker, 2014; Baker et al., 2016; Rathert, Wyrwich, \& Boren, 2013), informed policy or planning initiatives as well as accelerated work and its visibility (Baker, 2014), and improvement in patient experience (Baker et al., 2016). Some facilitators identified in the literature to enhance patient engagement or patient-centred care initiatives include (a) having a clear rationale for patient engagement and identifying the right patient engagement approach to achieve the desired outcomes, (b) dedicated champion and/or committed leadership that communicates strategic vision across the organization, (c) building staff capacity to work with patients, (d) having adequate resources, (e) organizational culture that is committed to change, (f) learning and involving patients in a meaningful way, and (g) clear roles and responsibilities (Armstrong et al., 2013; Baker, 2014; Baker et al., 2016; Luxford et al., 2011; Shaller \& Darby, 2009). Crawford et al. (2002) reported that staff attitudes toward collaborating with patients became more favourable compared to a baseline and that the organizational culture became more open to working with patients as a result.

Recent development of a public and patient engagement evaluation tool developed by Abelson et al. (2015) could be an important facilitator in advancing patient engagement and evaluating its impact. The tool was developed through a collaborative process that involved review of the literature as well as input from public and patient engagement researchers and practitioners. The four principles identified as critical for the evaluation of public and patient engagement are as follows: (a) integrity of design and process (i.e., diverse range of views, clear communication between organizers and participants, and support to enable participation), (b) influence and impact (i.e., informs planning/decision-making, learning, and increased confidence and trust), (c) participatory culture (i.e., organizational support for patient engagement, leaders informed on patient engagement, and demonstrated use of patient engagement work), and (d) collaboration and common purpose (i.e., plan and coordinate collaboratively to address concerns of people they serve). Despite the strengths of patient engagement in health service planning and evaluation, it does not come without its unique challenges. This next section will discuss some of the challenges faced when engaging patients in planning and evaluation initiatives. 


\section{Challenges to Patient Engagement}

The vagueness of the concept of patient engagement and the lack of clarity of purpose, structures, and roles among patients and health professionals involved in a patient engagement initiative were reported to challenge the patient engagement process (Armstrong et al., 2013; Baker, 2014; Crawford et al., 2002; Fudge et al., 2007; Gagliardi et al., 2008a; Tedford-Gold, Abelson, \& Charles, 2005). Some view patient engagement as a quality issue that can contribute to improvements of services, but others see it as simply an accountability requirement that can be accomplished with a single time point consultation rather than genuine engagement.

Studies examining patient experiences with patient engagement were mixed. Some patients reported that the engagement process was rewarding and appreciated the opportunity to be involved; other studies reported patient dissatisfaction with the process and lack of interest in being involved in health improvement initiatives (Fudge et al., 2007; Gagliardi et al., 2008a). There was also some reluctance on behalf of some health professionals to support shared decision-making with patients (Frosch, May, Rendle, Tietbohl, \& Elwyn, 2012). The variations in the valuing of patients' experiential knowledge resulted in some studies reporting a significant gap between their intentions to involve patients and what actually occurred. Finally, appropriate guidelines or approaches for engaging patients in health service planning and evaluation are quite lean. Participatory evaluation and research approaches to patient engagement have been suggested as a good starting point, but there is little published evidence that such approaches have been used (Armstrong et al., 2013; Bate \& Robert, 2007).

Methodologically, few studies examined the effectiveness or quality of their patient engagement approaches. Most studies examining patient engagement approaches were descriptive in nature and were generally restricted to authors' reflections on the strengths and limitations of their engagement process. To date, most patient engagement in program improvement initiatives have been consultative in nature rather than representing genuine interactive engagement sustained over time. Very few studies examined the patients' experiences or the impact of the engagement process on patients and health professionals involved in the patient engagement process; considering that the intent of patient engagement is to be more patient-centred, this is somewhat ironic (Fudge et al., 2007; Gagliardi et al., 2008a). Also of concern is the relative lack of collaboration and shared knowledge between the evaluation community and health sector related to patient engagement. Many of the strengths and challenges identified and discussed in the patient engagement literature have a long history in the evaluation literature. Evaluators have unique skills and evaluation approaches that could make significant contributions in ensuring that patient engagement prospers and ultimately improves the patient experience. In the next section, we provide an overview of collaborative approaches to evaluation and discuss how such approaches could serve the improvement of patient engagement processes and strengthening partnerships between patients and health service providers. 


\section{COLLABORATIVE APPROACHES TO EVALUATION AND PATIENT ENGAGEMENT}

The very nature of patient engagement in health service planning and evaluation implicates the use of collaborative and participatory approaches. Yet one of the barriers to patient engagement in health service planning and evaluation is the limited knowledge on how to put such approaches into practice (Fudge et al., 2007). Recent developments in the evaluation community, particularly with regard to the development and validation of principles for CAE (Shulha, Whitmore, Cousins, Gilbert, \& Al Hudib, 2016) offer useful guidance. CAE seeks to develop a partnership between the evaluator and members of the program or intervention community such as program developers and managers or service users (e.g., patients). Evaluators bring technical expertise and knowledge of evaluation professional standards of practice to the planning and evaluation process, and patients bring experiential knowledge with the interventions (i.e., health services) and a rich knowledge of the context in which the interventions are implemented (Cousins \& Chouinard, 2012; Cousins \& Earl, 1995; Stevahn, King, Ghere, \& Minnema, 2005). A key element to CAE is that stakeholders (e.g., patients, family members, health professionals, decision makers) are actively involved in decision-making and are able to see tangible evidence of their contributions. Of equal importance in CAE is attention to capacity-building designed to assist program community members to understand the evaluation process and their role in it. Cousins and Earl (1995) and Cousins and Chouinard (2012) view participatory approaches to evaluation as a means of enhancing the use of evaluation findings and working toward creating an organizational culture that is committed to learning and improvement. Learning not only involves quantitative standards from performance indicators, but from genuine collaboration between health practitioners/researchers and patients/family or process use (Patton, 1997).

Figure 1 elucidates the eight principles to guide CAE that were recently developed and validated by Shulha et al. (2016). A growing number of participatory approaches fall under the CAE umbrella (e.g., practical participatory evaluation, most significant change technique, rapid rural appraisal). Common to them all is that evaluators work in partnership with members of the program community. Three important considerations are associated with these principles: first, they are to be considered as a set, not as a pick-and-choose menu for application; second, they are well differentiated from yet overlapping and interconnected with one another; finally, they are not intended to imply a linear sequence, although there is a loose temporal order beginning with "Clarify the Motivation for Collaboration."

The principles can be used most importantly as a guide to CAE practice but also to retrospectively analyze projects, review evaluation policy, and inform professional development, among other applications. In the present case, the emphasis placed on the "participant's" central role in the evaluation process is of great interest since it parallels Mallett's (1996) definition of PCC, which emphasizes placing patients in the centre of the system of care. It is important to note that many types of CAE involve other stakeholders such as managers and implementers in evaluation 


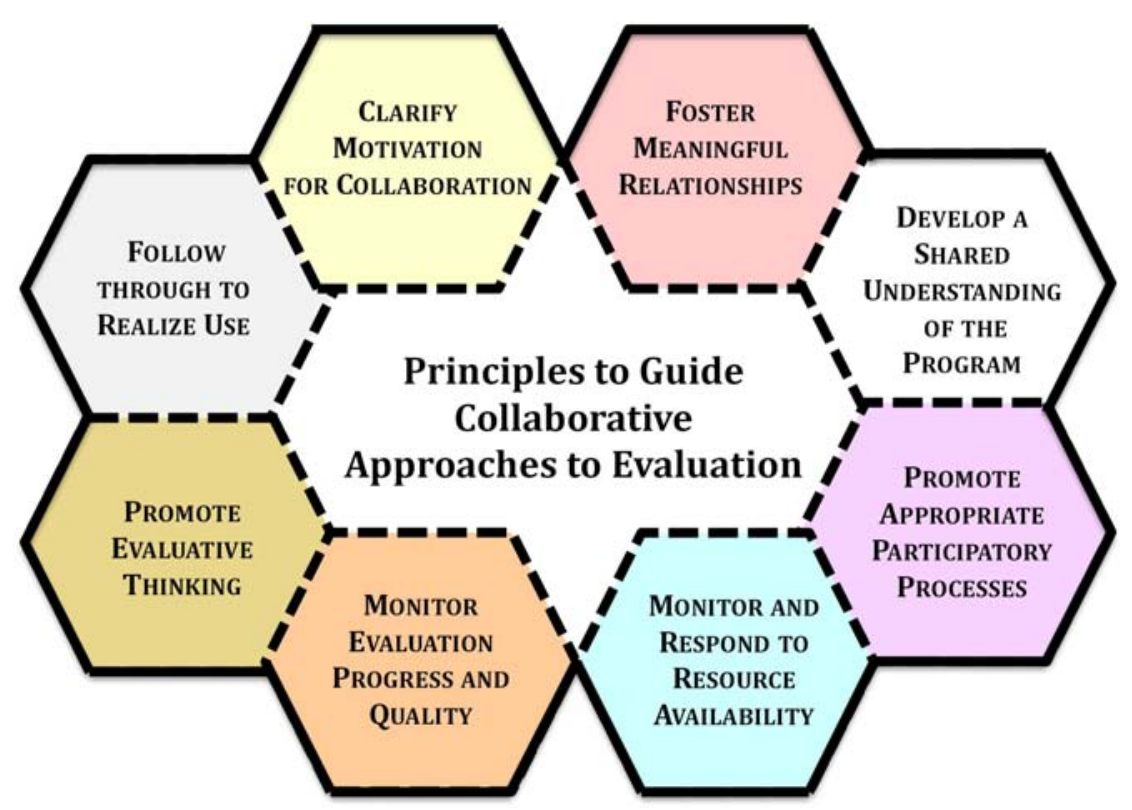

Figure 1. An Integrated Set of Principles for Use in Guiding Collaborative Approaches to Evaluation

processes; in addition, some also engage intended service or intervention beneficiaries, which would be critically important in the context of PCC.

Patient engagement provides patients with an opportunity to dialogue with health professionals about what is of importance to them as well as to be actively involved in decisions for improving health services, a key principle of PCC. However, recurring weaknesses from the patient engagement literature are the lack of guidance or approach to implementing patient engagement into practice, the gap between intentions to involve patients and their actual involvement, patient engagement tending to be more consultative than collaborative, and the challenges and time required to shift clinician attitudes to adopt a more "patient and family focus" to their practice (Baker, 2014; Fudge et al., 2007; Tedford-Gold et al., 2005). For example, in Gagliardi et al's (2008a) study, one of the suggested recommendations made by participants was that the patient engagement "process should be ongoing and interactive rather than single, passive efforts to enable information sharing, and foster mutual understandings of perspective among patients and health professionals" (p. 239). This type of recommendation bodes well for a patient engagement approach that is collaborative in nature, similar to CAE.

In considering justifications for CAE, Cousins and Whitmore (1998) identified two streams of participatory evaluation: (a) Practical Participatory Evaluation $(P-P E)$ and (b) Transformative Participatory Evaluation (T-PE). P-PE supports program or organizational decision-making and its main function is in fostering 
evaluation use. "The core premise of P-PE is that stakeholder participation in evaluation will enhance evaluation relevance, ownership, and thus utilization" (p. 6). The second rationale, T-PE, seeks to empower members of community groups who are less powerful and "invokes participatory principles and actions in order to democratize social change; it has quite different ideological and historical roots from P-PE" (p. 7). For the purpose of this article, the proposed use of participatory evaluation approaches would fall within the P-PE rationale. Despite there being an element of empowerment in patient engagement, the overall goal is to improve the quality of care while recognizing that the process of patient engagement has a very practical aspect to it. In addition, it promotes utilization of evaluation results by having decision makers involved throughout the evaluation process. It should be noted, however, that capacity building and empowerment outcomes may also occur in P-PE and that transformative and practical outcomes are by no means mutually exclusive.

Three fundamental dimensions of process in CAE have been identified by Cousins and Whitmore (1998) and affirmed by others (e.g., Daigneault \& Jacob, 2009). These dimensions, appearing in Figure 2, are considered to be orthogonal and represent decision points that help to shape the CAE process. The first is control of evaluation process - who controls the decision-making related to the technical aspects of the planning and evaluation process: researchers/evaluators, organizational decision makers (health professionals)/service users (patients), or some balance between the two? The second dimension is stakeholder diversity-who (e.g., program decision makers, patients, family, program staff) within the program or organization should be involved in the planning and evaluation process? The final dimension is depth of participation, implicating the intensity of involvement in the evaluation process, ranging from light touch consultation to significant engagement with all phases of evaluation planning and implementation.

We argue that widespread use of CAE in the context of PCC is lacking, but it has enormous potential to assist health organizations to leverage patient engagement in meaningful and sustainable ways. We advocate practical CAE approaches to broaden decision-making and problem-solving by engaging a range of key stakeholders in planning and conducting evaluation for health service quality improvement initiatives. Intended service beneficiaries (patients) would be the central figures among participating stakeholders, given compatibility with the principles of PCC. The direct use of the CAE principles to guide planning and evaluation efforts has considerable potential to assist health organizations to further their agenda of fostering patient engagement.

\section{CONCLUSION AND AGENDA FOR FUTURE RESEARCH}

Our survey of the patient engagement landscape, while likely not exhaustive, provides an overview of current quality improvement methods being used in the health sector as well as some of the complexities and challenges of engaging patients and health professionals in collaborative program improvement initiatives. 


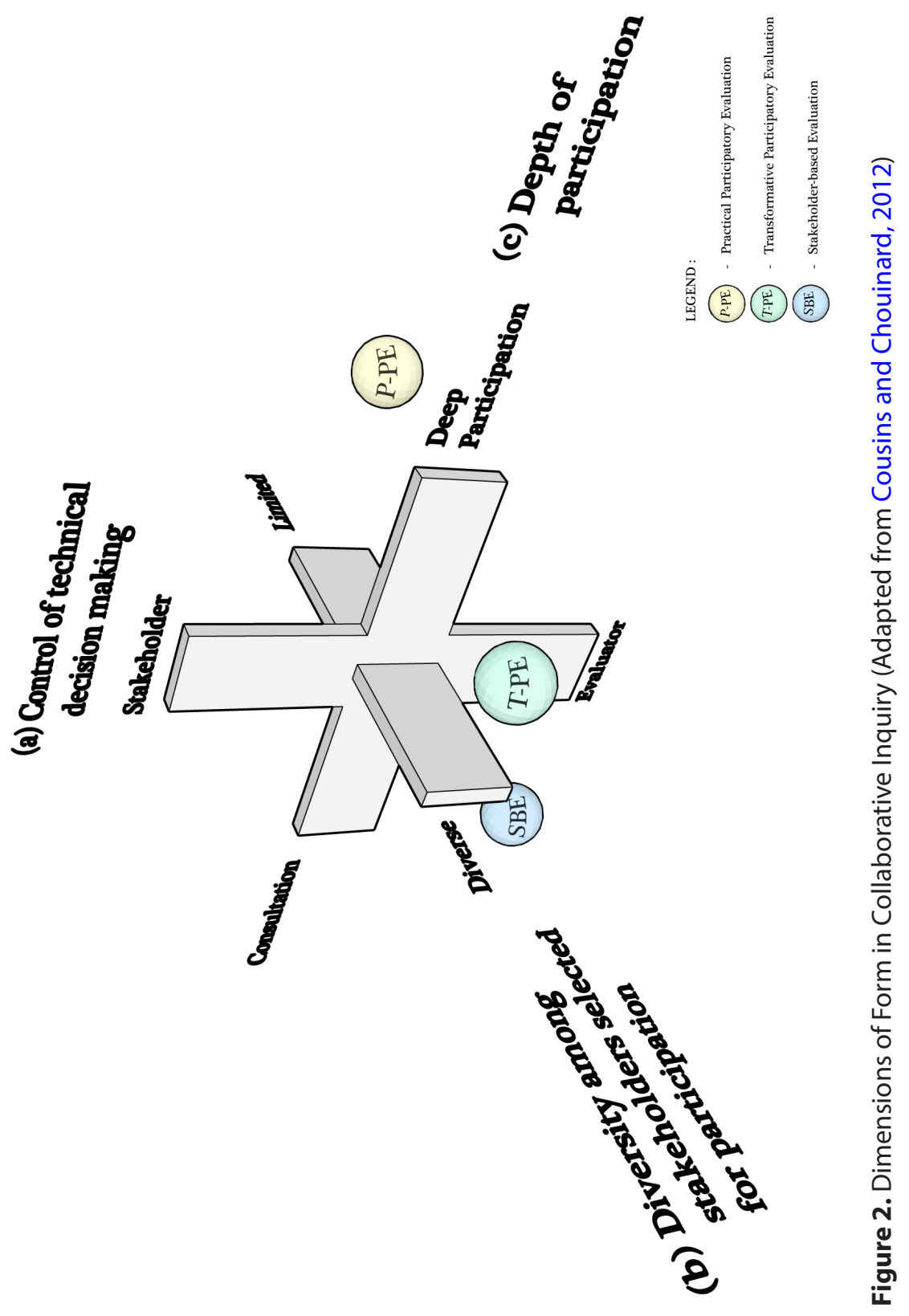


The complexity of engaging patients in planning and evaluation requires continued research that goes beyond examining patient engagement at the level of direct care, toward a better understanding of patient engagement at a program or system level. Despite emerging evidence that suggests patient engagement leads to patient and organizational improvements (Baker, 2014), we need to explore and gain a better understanding of the processes involved or evaluation approaches that could contribute to translating patient engagement into improved outcomes. In this final section, we identify priority issues and questions for study that we believe could help further our understanding of patient engagement in health care improvement.

1. Practical CAE: Despite significant effort, the extent to which patients have been engaged in health care quality improvement has mostly been limited to various forms of single time point consultation, rather than a genuine interactive partnership based on principles of CAE. Of interest would be the examination of practical forms of CAE for the development of effective engagement processes. Such activities carry significant potential to leverage evidence-based decision-making in the interest of service improvement.

2. Facilitators and barriers: In our review, few patient engagement initiatives evaluated or examined the patient's or health professional's experience with the engagement experience. How do patients feel about their engagement experience? What are some of the factors that facilitate or restrain patient engagement? To what extent does more intensive involvement in evaluation than is presently the case mediate such factors?

3. Process considerations: Do we know what approach is best suited to engage patients in the evaluation process? Principles for CAE implicate the development of deep understandings of context and the nature of interventions to inform subsequent process decisions such as (a) who controls the technical evaluation decision-making (evaluator, balanced, stakeholder)? (b) who from the health care community (e.g., managers, caregivers), apart from patients, should be involved in evaluation and why? (c) how intensive (light touch, deep involvement) should patient and other stakeholder engagement in evaluation be?

4. Understanding consequences: It is important to understand patient engagement consequences in the health care setting context. What are the observed effects of the engagement process? Has improved patient experience or patient centredness been achieved? What are the intended benefits of engaging patients in the planning and evaluation process? What are the unintended effects (positive or negative) of engaging patients in planning and evaluation processes? To what extent did these observed outcomes depend on process dynamics?

5. Capturing perspectives: We are of the view that alternative methodological approaches are required for assessing patient experience and the 
effects of patient engagement beyond measurement and patient feedback (i.e., patient satisfaction surveys, patient narratives). Performance data often fall short in informing decisions about issues that are of importance to patients, and patient satisfaction surveys are limited in terms of identifying areas that need improvement or learning about the patient experience. We would suggest complementing these strategies with ones that provide deeper understanding of the patient experience and help focus improvement efforts-for example, qualitative approaches, such as participant observation, as a means of giving primacy to what is meaningful to patients and focus improvements. In short, move beyond the reflective narrative in describing the patient engagement process and its impacts on PCC.

We have provided an overview of patient engagement within a health care context and identified important areas where we believe the evaluation community can play a significant role in continuing to advance the body of knowledge and practice of patient engagement. Our intention has been to explicate some options for more collaborative practice and to inform a future research agenda that will add new insights and advance our understanding of patient engagement. In the end, our hope is that research on patient engagement will help highlight the importance of including the patient perspectives to create a more responsive health care system.

\section{ACKNOWLEDGEMENTS}

The authors acknowledge financial support for this research provided by the University of Ottawa. The opinions expressed herein do not necessarily reflect those of the sponsoring agency.

\section{REFERENCES}

Abelson, J., Li, K., Wilson, G., Shields, K., Schneider, C., \& Boesveld, S. (2015). Supporting quality public and patient engagement in health system organizations: Development and usability testing of the Public and Patient Engagement Evaluation Tool (PPEET). Health Expectations, 9(4) , 817-827. http://dx.doi.org/10.1111/hex.12378

Abelson, J., Wagner, F., DeJean, D., Boesveld, S., Gauvin, F. P., Bean, S., . .., \& Lavis, J. (2016). Public and patient involvement in health technology assessment: A framework for action. International Journal for Health Assessment in Healthcare, 32(4), 256-264.

Adair, C., Simpson, E., Casebeer, A., Birdsell, J., Hayden, K. and Lewis, S. (2006). Performance measurement in healthcare: Part I - Concepts and trends from a state of the science review. Health Policy, 2(1), 85-104.

Agency for Healthcare Research and Quality. (2005). National Healthcare Quality Report (Research Report Publication No. 06-0018). Retrieved from https://archive.ahrq.gov/ qual/nhqr05/nhqr05.pdf 
Armstrong, N., Herbert, G., Aveling, E. L., Dixon-Woods, M., \& Martin, G. (2013). Optimizing patient involvement in quality improvement. Health Expectations, 16(3), e36-e47. http://dx.doi.org/10.1111/hex.12039

Baker, G. R. (2014). Evidence boost: A review of research highlighting how patient engagement contributes to improved care. Retrieved from Canadian Foundation for Healthcare Improvement website: http://www.cfhi-fcass.ca/sf-docs/default-source/ reports/evidenceboost-rossbaker-peimprovedcare-e.pdf?sfvrsn $=6$

Baker, G. R., Fancott, C., Judd, M., \& O'Connor, P. (2016). Expanding patient engagement in quality improvement and health system redesign. Healthcare Management Forum, 29(5), 176-182. http://dx.doi.org/10.1177/0840470416645601

Baker, R., \& Denis, J. L. (2011). A comparative study of three transformative health care systems: Lessons for Canada (Research Report ISBN: 978-1-927024-15-7). Retrieved from http://www.cfhi-fcass.ca/SearchResultsNews/11-10-26/0d3e9041-a834-45119f95-7c37ba287a79.aspx

Bate, P., \& Robert, G. (2007). Bringing user experience to healthcare improvement: The concepts, methods and practices of experience-based design. Abingdon, UK: Radcliffe.

Canadian Foundation for Healthcare Improvement. (2012). Myth: High patient satisfaction means high quality care. Retrieved from http://www.cfhi-fcass.ca/ PublicationsAndResources/Mythbusters/ArticleView/12-11-01/109897c8-c5254177-ad1b-66b6b63bdaf3.aspx

Canadian Foundation for Healthcare Improvement. (2017). Putting patients at the centre of their care. Retrieved from http://www.cfhi-fcass.ca/WhatWeDo/PatientEngagement

Canadian Institute for Health Information. (2016). Canadian Patient Experiences Survey - Inpatient care data dictionary manual. Retrieved from https://www.cihi.ca/en/ cpes_ic_dd_manual_en.pdf

Canadian Institutes of Health Research. (2016). Canada's Strategy for patient oriented research (SPOR). Retrieved from http://www.cihr-irsc.gc.ca/e/41204.html

Cancer Care Ontario. (2011). The 2011-2015 Ontario cancer plan. Retrieved from https:// www.cancercare.on.ca/common/pages/UserFile.aspx?fileId=84204

Carman, K., Dardess, P., Maurer, M., Sofaer, S., Adams, K., Bechtel, C., \& Sweeney, J. (2013). Patient and family engagement: A framework for understanding the elements and developing interventions and policies. Health Affairs, 32(2), 223-231. http://dx.doi. org/10.1377/hlthaff.2012.1133

Change Foundation. (2015). The Change Foundation 2015-2020 strategic plan. Retrieved from http://www.changefoundation.ca/2015-2020-strategic-plan/

Cousins, J. B., \& Chouinard, J. (2012). Participatory evaluation up close: A review and integration of research-based knowledge. Charlotte, NC: Information Age Press.

Cousins, J. B., \& Earl, L. M. (1995). The case for participatory evaluation: Theory, research, practice. In B. Cousins \& L. Earl (Eds.), Participatory evaluation in education: Studies in evaluation use and organizational learning (pp. 3-18). London, UK: Falmer Press.

Cousins, J. B., \& Whitmore, E. (1998). Framing participatory evaluation. In E. Whitmore (Ed.), Understanding and practicing participatory evaluation. New Directions in Evaluation (pp. 3-23). San Francisco, CA: Jossey-Bass. http://dx.doi.org/10.1002/ev.1114 
Crawford, M., Rutter, D., Manley, C., Weaver, T., Bhui, K., Fulop, N., \& Tyrer, P. (2002). Systematic review of involving patients in the planning and development of health care. British Medical Journal, 325, 1-5.

Daigneault, P. M., \& Jacob, S. (2009). Toward accurate measurement of participation: Rethinking the conceptualization and operationalization of participatory evaluation. American Journal of Evaluation, 30(3), 330-348. http://dx.doi.org/ $10.1177 / 1098214009340580$

Davies, E., \& Cleary, P. D. (2005). Hearing the patient's voice? Factors affecting the use of patient survey data in quality improvement. Quality \& Safety in Health Care, 14(6), 428-432. http://dx.doi.org/10.1136/qshc.2004.012955

Frosch, D. L., May, S. G., Rendle, K. A., Tietbohl, C., \& Elwyn, G. (2012). Authoritarian physicians and patients' fear of being labeled "difficult" among key obstacles to shared decision making. Health Affairs, 31(5), 1030-1038. http://dx.doi.org/10.1377/ hlthaff.2011.0576

Fudge, N., Wolfe, C. D. A., \& McKevitt, C. (2007). Assessing the promise of user involvement in health service development: Ethnographic study. British Medical Journal, 336(313), 1-8.

Gagliardi, A. R., Lemieux-Charles, L., Brown, A. D., Sullivan, T., \& Goel, V. (2008a). Barriers to patient involvement in health service planning and evaluation: An exploratory study. Patient Education and Counseling, 70(2), 234-241. http://dx.doi.org/10.1016/j. pec.2007.09.009

Gagliardi, A. R., Lemieux-Charles, L., Brown, A. D., Sullivan, T., \& Goel, V. (2008b). Stakeholder preferences for cancer care performance indicators. International Journal of Health Care Quality Assurance, 21(2), 175-189. http://dx.doi. org/10.1108/09526860810859030

Gerteis, M., Edgman-Levitan, S., Daley, J., \& Delbanco, T.L. (Eds.). (1993). Through the patient's eyes: Understanding and promoting patient-centered care. San Francisco, CA: Jossey-Bass.

Hill, P., O’Grady, A., Millar, B., \& Boswell, K. (2000). The patient care development programme: Organisational development through user and staff involvement. International Journal of Health Care Quality Assurance, 13(4), 153-161. http://dx.doi. org/10.1108/09526860010336957

Institute of Medicine. (2001). Crossing the quality chasm: A new health system for the 21st century. Retrieved from http://www.nap.edu/openbook.php?record_id=10027

International Alliance of Patients' Organization. 2007. What is patient-centered healthcare? A review of definitions and principles. Retrieved from http://iapo.org.uk/sites/ default/files/files/IAPO\%20Patient-Centred\%20Healthcare\%20Review\%202nd\%20 edition.pdf

Ioan, B., Nestian, A., \& Tiţă, S.-M. (2012). Relevance of key performance indicators (KPIs) in a hospital performance management model. Journal of Eastern Europe Research in Business \& Economics, 1-15. http://dx.doi.org/10.5171/2012.674169

Kötter, T., Schaefer, F.A., Scherer, M., \& Blozik, E. (2013). Involving patients in quality indicator development: A systematic review. Patient Preference and Adherence, 7, 259-268. http://doi.org/10.2147/PPA.S39803 
Little, P., Everitt, H., Williamson, I., Warner, G., Moore, M., \& Gould, C. (2001). Preferences of patients for patient-centered approach to consultation in primary care: Observation study. BMJ (Clinical Research Ed.), 322(7284), 468-472. http://dx.doi.org/10.1136/ bmj.322.7284.468

Luxford, K., Safran, D. G., \& Delbanco, T. (2011). Promoting patient-centred care: A qualitative study of facilitators and barriers in healthcare organizations with a reputation for improving the patient experience. International Journal for Quality in Health Care, 23(5), 510-515. http://dx.doi.org/10.1093/intqhc/mzr024

Mallett, J. (1996). Sense of direction. Nursing Times, 92, 40-42.

Martin, N., \& Ronson, J. (2007). Opinions: Patient satisfaction surveys: Another view. Healthcare Quarterly, 10(3), 8. http://dx.doi.org/10.12927/hcq.2007.18916

Ministry of Health and Long-Term Care. (2015). Patients first: Action plan for health care. Retrieved from http://www.health.gov.on.ca/en/ms/ecfa/healthy_change/

Mitton, C., Smith, N., Peacock, S., Evoy, B., \& Abelson, J. (2009). Public participation in health care priority setting: A scoping review. Health Policy (Amsterdam), 91(3), 219-228. http://dx.doi.org/10.1016/j.healthpol.2009.01.005

Patton, M. Q. (1997). Utilization-focused evaluation. Thousand Oaks, CA: Sage.

Ponte, P. R., Conlin, G., Conway, J. B., Grant, S., Medeiros, C., Nies, J., . . ., Conley, K. (2003). Making patient-centered care come alive: Achieving full integration of the patient's perspective. Journal of Nursing Administration, 33(2), 82-90. http://dx.doi. org/10.1097/00005110-200302000-00004

Rao, J. K., Weinberger, M., \& Kroenke, K. (2000). Visit-specific expectations and patientcentered outcomes: A literature review. Archives of Family Medicine, 9(10), 1148-1155. http://dx.doi.org/10.1001/archfami.9.10.1148

Rathert, C., Wyrwich, M. D., \& Boren, S.A. (2013). Patient-centered care and outcomes: A systematic review of the literature. Medical Care Research and Review, 70(4), 351-379. http://dx.doi.org/10.1177/1077558712465774

Robinson, J., Callister, L., Berry, J., \& Dearing, K. (2008). Patient-centered care and adherence: Defintions and applications to improve outcomes. Journal of the American Academy of Nurse Practitioners, 20(12), 600-607. http://dx.doi.org/10.1111/j.17457599.2008.00360.x

Shaller, D. (2007). Patient centered care: What does it take? (Commonwealth Fund publication number 1067). Retrieved from http://www.commonwealthfund.org/usr_doc/ Shaller_patient-centeredcarewhatdoesittake_1067.pdf

Shaller, D., \& Darby, C. (2009). High performing patient and family academic medical centers: Cross site summaries of six case studies: Picker Institute. Retrieved from http://www. upstate.edu/gch/about/special/picker_report_7_09.pdf

Shulha, L. M., Whitmore, E., Cousins, J. B., Gilbert, N., \& Al Hudib, H. (2016). Introducing evidence-based principles to guide collaborative approaches to evaluation: Results of an empirical process. American Journal of Evaluation, 37(2), 193-215. http://dx.doi. org/10.1177/1098214015615230

Stevahn, L., King, J. A., Ghere, G., \& Minnema, J. (2005). Establishing essential competencies for program evaluators. American Journal of Evaluation, 26(1), 43-59. http:// dx.doi.org/10.1177/1098214004273180 
Stewart, M., Brown, J. B., Donner, A., McWhinney, I. R., Oates, J., Weston, W. W., \& Jordan, J. (2000). The impact of patient-centered care on outcomes. Journal of Family Practice, 49, 796-804.

Tedford Gold, S., Abelson, J., \& Charles, C. (2005). From rhetoric to reality: Including patient voices in supportive cancer care planning. Health Expectations, 8(3), 195-209. http://dx.doi.org/10.1111/j.1369-7625.2005.00334.x

Van de Bovenkamp, H., Trappenburg, M., \& Grit, K. (2010). Patient participation in collective healthcare decision making: The Dutch model. Health Expectations, 13(1), 73-85. http://dx.doi.org/10.1111/j.1369-7625.2009.00567.x

Veillard, J., Champagne, F., Klazinga, N., Kazandjian, V., Arah, O. A., \& Guisset, A. L. (2005). A performance assessment framework for hospitals: The WHO regional office for Europe PATH project. International Journal for Quality in Health Care, 17(6), 487-496. http://dx.doi.org/10.1093/intqhc/mzi072

Williams, B., Coyle, J., \& Healy, D. (1998). The meaning of patient satisfaction: An explanation of high reported levels. Social Science \& Medicine, 47(9), 1351-1359. http:// dx.doi.org/10.1016/S0277-9536(98)00213-5

\section{AUTHOR INFORMATION}

Nathalie Gilbert is a Ph.D. candidate in the Faculty of Education, University of Ottawa. Her research interests are in collaborative approaches to evaluation, and she is currently conducting research examining the process and impacts of engaging patients and their families in the planning and evaluation of health services.

J. Bradley Cousins is Professor Emeritus of Evaluation at the Faculty of Education, University of Ottawa. Cousins' main interests in program evaluation include participatory and collaborative approaches, use, and capacity building. Throughout his career he has published many articles and books on evaluation, received several awards for his work and served as the editor of the Canadian Journal of Program Evaluation from 2002 to 2010. 